\title{
Ensino da argumentação: construindo práticas
}

Teaching of argumentation: constructing practices

Telma Ferraz Leal

Ana Carolina Perrusi Brandão

Universidade Federal de Pernambuco

\section{Resumo}

Este artigo, com base em pressupostos sociointeracionistas, tem o objetivo de analisar situações didáticas com potencial para desenvolver habilidades argumentativas dos alunos. Foram observadas 15 aulas de cinco professoras do $5^{\circ}$ ano do Ensino Fundamental de escolas públicas. As aulas foram registradas em áudio e a abordagem de análise de conteúdo orientou o tratamento dos dados. Setenta e cinco relatórios de aulas foram analisados. Constatou-se que as professoras propõem discussões orais, atividades de leitura e produção de textos que demandam habilidades argumentativas. Entretanto, a condução dessas propostas não favorece o desenvolvimento das capacidades de produzir textos da ordem do argumentar e nem de leitura crítica de textos, com confronto de pontos de vista.

Palavras-chave: Argumentação. Leitura. Produção de textos.

\section{Abstract}

In this article, based on socio interactionist perspective, we aim to analyze didactical situations that show potential for developing student's argumentation skills. We have observed 15 classes of five elementary public school teachers. The classes were recorded in audio and we used content analysis to the data examination. We have analyzed 75 class reports and found out that teachers suggest oral discussions, reading activities and text production that demands argumentative abilities. Nevertheless, those proposals management do not favor either the development of text production capabilities regarding argumentation or text critical reading, with points of view confrontation.

Keywords: Argumentation. Reading. Text production. 


\section{Considerações iniciais}

$\bigcirc$ que os professores ensinam às crianças nos anos iniciais do ensino fundamental? Quais são as prioridades? Há clareza sobre quais seriam as expectativas de aprendizagem relativas às habilidades de leitura, escrita e oralidade? As habilidades argumentativas fazem parte do rol de objetivos didáticos nesse segmento de ensino?

Tais questões estão presentes no cotidiano dos professores. Sem dúvida, delimitar o que ensinar, em cada etapa de escolaridade, é um desafio constante. Incluir o trabalho voltado para o desenvolvimento de habilidades argumentativas no elenco de prioridades parece ser um desafio ainda maior, visto que, nem sempre, se tem muita clareza sobre quais seriam tais habilidades ou sobre quando ou como realizar tal ensino. No entanto, é comum ouvir declarações de que cabe à escola a formação de sujeitos críticos, que possam se posicionar sobre a realidade vivida, que possam agir para defender direitos e para combater preconceitos. Desse modo, a discussão sobre as relações entre argumentação e educação é uma necessidade no contexto educacional atual.

Em pesquisa anterior em que foram investigadas propostas curriculares de Língua Portuguesa de sete capitais brasileiras, evidenciou-se que, em seis delas, havia indicações de habilidades argumentativas a serem contempladas nos anos iniciais do Ensino Fundamental. No entanto, nos documentos analisados foram encontradas poucas orientações didáticas que pudessem ajudar os professores no ensino de tais habilidades.

Considerando, a partir desses resultados, que a argumentação integra o rol de objetos de aprendizagem a serem contemplados na escola, buscou-se entender quais seriam as concepções e práticas das professoras em relação a esse objeto. Nessa direção, procedeu-se a uma pesquisa sobre o ensino da argumentação nos anos iniciais do Ensino Fundamental.

\section{Fundamentos teóricos e metodológicos}

Para explorar as situações didáticas envolvendo o ensino da argumentação nos anos iniciais do Ensino Fundamental, a pesquisa desenvolvida contemplou diferentes instrumentos de coleta de dados aplicados em distintas 
etapas da investigação. Neste artigo, será enfocada, apenas, uma dessas etapas: a que envolveu observações de aulas de cinco professoras do $5^{\circ}$ ano de escolas públicas do Recife.

Foram observadas e gravadas em áudio 15 aulas de cada docente. Em seguida, com apoio das anotações realizadas durante as observações e das transcrições dos dados, foram produzidos 75 relatórios de aula.

Para a interpretação do material coletado, foi adotada a análise de conteúdo de Bardin (2004, p. 89), que propõe três fases no tratamento dos dados. Na fase denominada de pré-análise, foi feita uma exploração geral dos 75 relatórios de aula, buscando, como recomenda o autor, [...] tornar operacionais e sistematizar as idéias iniciais, de maneira a conduzir a um esquema preciso do desenvolvimento das operações sucessivas, num plano de análise." Foram, assim, construídas as primeiras categorias analíticas.

Na segunda etapa, procedeu-se à exploração do material, para aprimoramento dos procedimentos metodológicos. Segundo Bardin (2004), essa fase tem como finalidade "a administração sistemática das decisões tomadas" (p. 95). Nessa fase, as categorias foram revistas e os relatórios foram relidos para o preenchimento dos quadros de análise construídos.

Por fim, foi efetivada a etapa de tratamento dos resultados em que todos os relatórios foram novamente lidos e explorados, para o aprofundamento necessário das reflexões. Nessa fase, conforme destaca Bardin (2004, p. 95), "[...] o analista pode propor inferências e adiantar interpretações a propósito dos objetivos previstos." A partir dessa análise cuidadosa, identificaram-se as aulas em que algumas habilidades argumentativas foram mobilizadas, sendo essas analisadas novamente, na tentativa de identificar as estratégias didáticas adotadas. Assim, buscou-se reconhecer as concepções que estavam subjacentes às opções metodológicas e as possíveis dificuldades para condução do trabalho pedagógico.

Para a realização das análises dos relatórios das aulas observadas, foi adotada uma perspectiva sociointeracionista de argumentação, pois, como é exposto por Souza (2003, p. 16-17), "[...] na prática social, a todo o momento somos chamados a tomar decisões, julgar e influenciar o outro, avaliar, justificar, expor um ponto de vista, contrapor uma opinião etc." Para participar dessas situações, são mobilizados gêneros textuais específicos em 
que estratégias discursivas diversas conduzem os leitores / ouvintes ao debate social.

Desse modo, a abordagem dos gêneros textuais serviu de base para as reflexões, assumindo-se que,

[...] três elementos (conteúdo temático, estilo e construção composicional) fundem-se indissoluvelmente no todo do enunciado, e todos eles são marcados pela especificidade de uma esfera de comunicação. Qualquer enunciado considerado isoladamente é, claro, individual, mas cada esfera de utilização da língua elabora seus tipos relativamente estáveis de enunciados, sendo isso que denominamos gêneros do discurso. (BAKHTIN, 2000, p. 279).

Tal opção decorre do pressuposto bakhtiniano de que

[...] ignorar a natureza do enunciado e as particularidades de gênero que assinalam a variedade do discurso em qualquer área do estudo lingǘístico leva ao formalismo e à abstração, desvirtua a historicidade do estudo, enfraquece o vínculo existente entre a língua e a vida. (BAKHTIN, 2000, p. 282).

Assim, buscou-se analisar se as atividades desenvolvidas em sala de aula se assemelhavam às atividades de leitura, escrita e oralidade praticadas nas diversas esferas de interação social. Mais especificamente, foram examinadas as propostas em que as professoras pretendiam ensinar as crianças a lidar com textos em situações em que a argumentação faz-se presente, ou seja, os textos da ordem do argumentar.

Segundo Dolz e Schneuwly (2004), a expressão - textos da ordem do argumentar - é utilizada para agrupar os gêneros textuais que apresentam como característica principal sequências tipológicas argumentativas e têm por função a sustentação, refutação e negociação de tomadas de posição.

Desse modo, em consonância com tais teóricos, percebe-se que os textos da ordem do argumentar são utilizados nas situações de interação nas quais diferentes pontos de vista são possíveis e pelos quais os interlocutores buscam orientar os seus discursos a determinadas conclusões: buscam convencer e podem ser convencidos. $\bigcirc$ confronto de opiniões e a possibilidade de existência de diferentes pontos de vista sobre o tema, portanto, são características fundamentais dos textos da ordem do argumentar. Exemplos de gêneros 
mobilizados para a construção de textos são o debate, o artigo de opinião, o editorial, a carta de reclamação, dentre outros.

Neste artigo, como já foi dito, analisaram-se as aulas de cinco docentes do $5^{\circ}$ ano, buscando investigar se essa característica central da argumentação - a de possibilitar confronto de pontos de vista - era considerada no desenvolvimento de atividades em que as habilidades argumentativas eram mobilizadas.

\section{Análise dos resultados}

Considerando o total de 75 aulas observadas, em apenas seis aulas foram encaminhadas propostas didáticas que envolviam o trabalho com argumentação. Assim, foram raras as atividades de leitura e de produção de textos realizadas com a finalidade de ensinar a lidar com situações que mobilizavam a compreensão, expressão e confronto de diferentes pontos de vista.

Em um estudo anterior, foram discutidos as possíveis razões para esse baixo investimento com base na análise de entrevistas com 14 docentes e observações de aulas nos $1^{\circ}$ e $5^{\circ}$ anos do Ensino Fundamental. Na investigação, foi evidenciado que as professoras consideravam importante ajudar os estudantes a desenvolver estratégias argumentativas e acreditavam que eles eram capazes de aprender a argumentar logo cedo. No entanto, não tinham conhecimentos sistematizados sobre o que poderia ser ensinado (quais habilidades / capacidades argumentativas) ou como isso poderia ser feito. Declaravam, inclusive, dificuldades para reconhecer quais gêneros discursivos seriam potencialmente mais favoráveis à realização de atividades voltadas para o desenvolvimento de habilidades argumentativas.

Tais dificuldades, na realidade, refletem o estado da arte sobre a temática da argumentação que, além de ser pouco debatida nos cursos de formação de professores, é polêmica. De fato, as professoras entrevistadas, no estudo referido acima, não faziam alusão às leituras ou às discussões sobre o ensino da argumentação nos anos iniciais do Ensino Fundamental em seus cursos de formação inicial ou continuada. Nos livros didáticos, também são poucas as atividades de leitura ou de produção de textos com foco em capacidades argumentativas nesse segmento de ensino. (ANDRADE, LEAL \& BRANDÃO, 2006; BEZERRA, 200 1; REINALDO, 2001; MENDONCCA, 2001; 
LOPES, 1998; BRASSART, 1990). E há ainda os que consideram que não seria adequado ou necessário introduzir atividades didáticas com objetivos dessa natureza no início da escolarização.

Apesar do pouco auxílio recebido, vimos, evidencia-se, no entanto, que as docentes observadas consideravam que o ensino das capacidades argumentativas deveria ser contemplado desde o início da escolarização, sendo constatadas algumas tentativas nessa direção. Assim, mesmo sem orientações para um trabalho pedagógico voltado para essa dimensão da interação humana, as professoras praticavam, em suas aulas, estratégias didáticas para ajudar os estudantes a desenvolver habilidades que possibilitassem uma participação mais "crítica" na sociedade. É com base em fenômenos como esse que Oliveira (2008) afirma que

Os educadores e educadoras que estão nas escolas tecem redes de práticas pedagógicas que, através de "usos e táticas" de praticantes que são, inserem na estrutura social / curricular criatividade e pluralidade, modificadores das regras e das relações entre o poder instituído e a vida dos que a ele estão, supostamente, submetidos. (OLIVEIRA, 2008, p. 44-45).

Apesar da escassez de estudos sobre o tema (didática do ensino da argumentação nos anos iniciais do Ensino Fundamentall), da escassez de proposições nos livros didáticos e da carência de orientações nas Propostas Curriculares, as tentativas das docentes evidenciam que, assim como se vem defendendo em vários estudos, "[...] a prática docente não é mera repetição de fazeres previstos e/ou planejados de fora das salas de aula." IOLIVEIRA, 2008, p. 43). Os professores constroem suas próprias experiências.

No entanto, tal como se verifica neste estudo, muitas vezes, a precariedade do processo formativo e, certamente, das condições de trabalho impõem limites às tentativas dos docentes para concretizar suas intenções didáticas.

Em suma, este artigo não visa, simplesmente, mostrar as evidências para a baixa frequência de atividades voltadas para o ensino da argumentação. Pretende-se, na realidade, refletir sobre as situações em que as docentes de forma mais consciente ou intuitiva desenvolveram estratégias didáticas para o trabalho com argumentação. Desse modo, busca-se, analisar as práticas de ensino de capacidades que raramente vêm sendo enfocadas, quer nos cursos de formação inicial ou continuada, quer nos livros didáticos. 
Para melhor discussão desses dados, será apresentada a síntese do que foi observado nas aulas de cada docente, com vistas a contextualizar suas práticas, teorizando sobre os momentos quando foram mobilizados conhecimentos e habilidades relativos à aprendizagem da argumentação. Ao final, serão feitas exporemos algumas conclusões provisórias acerca das dificuldades identificadas nas práticas das professoras.

\section{Professora 1}

A professora 1 tinha 39 anos, com 21 anos de experiência de ensino. Era formada em Pedagogia e especialista em Políticas Educacionais. Ministrava aulas em uma turma de 36 alunos e se mostrava bastante interessada em promover um ensino em uma perspectiva interacionista.

Utilizava textos variados em suas aulas: poema, letra de música, biografia, relato histórico, definição, lista, roteiro de trabalho, texło didático. No entanto, não havia diversificação de suportes textuais. Via de regra, os alunos tinham acesso, apenas, aos textos dos livros didáticos, já que esses preenchiam o critério de diversidade textual, um aspecto muito valorizado pela docente. Essa tendência à diversificação dos gêneros em sala de aula pode ser interpretada como uma influência da teoria dos gêneros discursivos fundada nas formulações de Bakhtin (2000). Esse autor evidenciou a dimensão interativa da linguagem, apontando os gêneros discursivos como objetos culturais que são apropriados pelos participantes das diferentes situações de interlocução:

Em cada época de seu desenvolvimento, a língua escrita é marcada pelos gêneros do discurso e não só pelos gêneros secundários (literários, científicos, ideológicos), mas também pelos gêneros primários los tipos do diálogo oral: linguagem das reuniões sociais, dos círculos, linguagem familiar, cotidiana, linguagem sociopolítica, filosófica etc.). A ampliação da língua escrita que incorpora diversas camadas da língua popular acarreta em todos os gêneros (literários, científicos, ideológicos, familiares etc.) a aplicação de um novo procedimento na organização e na conclusão do todo verbal e uma modificação do lugar que será reservado ao ouvinte ou ao parceiro, etc., o que leva a uma maior ou menor reestruturação e renovação dos gêneros do discurso. (BAKHTIN, 2000, p. 285-286). 
Com base em Bakhtin, diferentes autores começaram a apontar que "[...] é através dos gêneros que as práticas de linguagem encarnam-se nas atividades dos aprendizes." (SCHNEUWLY; DOLZ, 1999, p. 6). Para pesquisadores como Jauss (1970) e Canvat (1996), os gêneros funcionam como modelos comuns que criam horizontes de expectativas para os membros de uma comunidade confrontados às mesmas práticas de linguagem.

Apesar de uma prática que contemplava o trabalho com os diferentes gêneros discursivos, não havia momentos de reflexão sobre as regularidades desses gêneros. Assim, ao que parece, estava subjacente a ideia de que os estudantes aprenderiam a interagir por meio dos gêneros, simplesmente, tendo acesso a eles nas situações em que tais textos estavam presentes.

Além disso, notara-se que a exploração dos textos obedecia a um padrão bastante regular: ler o texto; responder, oralmente, às questões elaboradas pela professora; responder, por escrito, questões dos livros didáticos ou elaboradas pela docente. De modo geral, às questões orais eram respondidas coletivamente, com possibilidade de comparação entre as respostas, e as questões escritas eram respondidas individualmente, o que diminuía a possibilidade de socialização de saberes e de compartilhamento de dúvidas.

186 Tal padrão didático vem sendo observado em muitas práticas de ensino e é também um modelo comum nos livros didáticos. Isto é, ler, para responder a perguntas, é uma prática antiga e recorrente nas escolas.

Em relação ao desenvolvimento de habilidades argumentativas, alguns dos materiais escritos selecionados possibilitavam, pela temática e pelas intenções subjacentes ao texto, reflexões sobre posicionamentos implícitos e explícitos acerca de temas sociais. Os textos escolhidos em três aulas potencializavam reflexões sobre posicionamento dos autores sobre os temas tratados, mas em apenas um dia, os alunos discutiram uma questão que exigia, de modo mais efetivo, capacidades argumentativas. É sobre essa tentativa que cabe uma reflexão.

Nesse dia, eles assistiram ao filme Tarzan II. Após o término do filme, as crianças fizeram, individualmente, a seguinte tarefa:

\section{TAREFA DE CLASSE}

Assistimos "Tarzan II", um filme dos Estúdios Walt Disney. Lembre a história e responda a seguir: 
1) Por que Tarzan ficou triste e resolveu fugir?

2) Na sua opinião, fugir de alguma situação resolve? Por quê?

3) O que ele encontrou ao se esconder na grande montanha?

4) Cada personagem estava envolvido numa situação não muito confortável:

Tarzan - sem família

Uma macaca solitária - cuidando sozinha de seus dois filhos

A mãe de Tarzan - muito triste com a perda do filho

Zugor - Tão solitário que, para se defender, inventou um monstro que não existia.

Na sua opinião, quais sentimentos foram mostrados no filme para resolver os problemas dos personagens?

A questão "Na sua opinião, fugir de alguma situação resolve? Por quê?" é particularmente interessante no trabalho voltado para o ensino da argumentação. Pedir aos estudantes que deem opinião sobre uma atitude tão comum na vida ordinária (fugir dos problemas) é uma forma de articular a vivência escolar à extraescolar. Na verdade, a professora solicitou das crianças uma extrapolação do que foi visto em sala de aula, pois não era, apenas, o personagem que estava sendo julgado, mas também as pessoas comuns. Ao refletirem sobre tal tipo de questão, sem dúvida, as crianças depararam-se com diferentes pontos de vista, já que, muitas vezes, as pessoas, por razões diversas, veem-se em situações em que optam por fugir/afastar-se dos problemas que surgem. Assim, após assistirem ao filme, a professora levou os alunos a usar a experiência narrada para pensar sobre suas próprias experiências.

Na aula descrita, a docente demonstrou, portanto, um envolvimento com o desenvolvimento pessoal das crianças ao abordar uma atitude humana e suas consequências. Oliveira (2008) também salienta a importância desse tipo de preocupação, ao analisar as experiências de um professor de Matemática denominado na pesquisa como Cássio. Sobre esse docente, a autora afirma que

Na medida em que buscava desenvolver uma metodologia de ensino mais eficiente, Cássio, ao mesmo tempo, incorporava ao currículo de sua disciplina questões relacionadas ao convívio social, aos problemas enfrentados pelo brasileiro comum em seu dia a dia. (OLIVEIRA, 2008, p. 56). 
Conforme a aula aqui analisada, a professora buscou discutir acerca de valores, informações ou temas mobilizados em filmes, uma proposta didática que mobiliza habilidades argumentativas importantes que podem ser transferidas para inúmeras situações do nosso cotidiano.

\section{Professora 2}

A professora 2 tinha 45 anos, era formada em Pedagogia e estava lecionando há 19 anos. A docente também trabalhava como coordenadora em outra escola, pela manhã, e, à tarde, era a professora de uma sala do $5^{\circ}$ ano com 31 alunos.

A análise das aulas apontou que a professora buscava promover situações de leitura em uma perspectiva interacionista, trazendo para a sala diferentes gêneros textuais: poema, conto, lenda, reportagem, receita culinária, cartaz educativo, texto didático, em diferentes suportes: revistas, livros literários, livro de receita, livros didáticos.

Em 10 aulas, foram observadas atividades de compreensão textual, sendo identificadas três aulas em que foram selecionados textos que apresentavam alto potencial para exploração de dimensões argumentativas.

Em uma dessas aulas, após a leitura da reportagem "A vida cercada de ameaças", retirada da revista "Terra: um mundo por conhecer e preservar" (São Paulo: abril, 85. Ed., ano 8, n.5 maio 1999. p. 28), a professora chamou os alunos para discutir o texto. No texto, os leitores foram estimulados a identificar o ponto de vista do autor e seus argumentos para preservar o planeta. Porém, logo após as primeiras intervenções das crianças, ela iniciou outra atividade, não aprofundando a discussão sobre o texto.

Numa outra aula observada, o texto utilizado possibilitava reflexões sobre diferenças sociais. $O$ poema "O meu bairro" retratava a realidade do bairro de um garoto. A docente perguntou aos alunos quais as sugestões que eles dariam para se conviver melhor no bairro, mas também não explorou as respostas dadas.

Percebeu-se, nas duas aulas citadas acima, que a professora conseguia selecionar textos e propor temáticas favoráveis à realização de atividades 
voltadas para o desenvolvimento de habilidades argumentativas. No entanto, falhava na condução da discussão, abreviando o momento do debate.

Numa outra aula, a docente trabalhou interpretação oral e escrita de um texto, retirado do livro didático, que tratava sobre as relações entre seres vivos. Havia, subjacente ao texto, uma ideia de que é importante que o homem mantenha boa relação com outros seres vivos. Nessa aula, a professora fez as seguintes perguntas, a serem discutidas em duplas: a) Na sua opinião, o fítulo do texto tem relação com o que está escrito nele? Por quê?; b) No ambiente onde você vive, como os humanos se relacionam com os demais seres vivos e não vivos? Na primeira pergunta, nota-se que o texto em si foi objeto de reflexão, sendo os alunos chamados a refletir sobre as relações de sentido entre o título e o texto como um todo. Na segunda questão, eles foram levados a julgar a atitude dos homens frente a outros animais, trazendo o tema do texto para as suas vidas. Foi registrada, ainda, uma aula em que a professora solicitou a escrita de um texto para defender um ponto de vista. Para isso, os alunos fizeram um levantamento sobre reportagens tratando do tema do meio ambiente, com vistas a escrever "um texto que fale do meio ambiente, a partir do que a reportagem trazia". A análise dessa única aula em que poderia haver desenvolvimento de capacidades de produção de textos da ordem do argumentar evidenciou uma grande dificuldade da docente relativa ao ensino da escrita de textos. Assim, os alunos não tinham clareza sobre a finalidade, o gênero ou mesmo o interlocutor do texto a ser produzido.

Schneuwly (1988), ao investigar os processos cognitivos de produção de textos, atenta para a relevância das condições de elaboração textual. O autor aponta evidências de que uma etapa importantíssima do processo de produção de textos é a construção de uma base de orientação, que é o conjunto de representações sobre a situação de escrita (finalidade, destinatário, espaço social de interação, papéis sociais dos interlocutores...): situação interna, criada a partir do contexto de interação - modificável à medida das necessidades e das mudanças do contexło social e material da atividade. $\bigcirc$ produtor do texto gerencia todo o processo de construção textual a partir dessa base de orientação. Se as condições escolares de escrita não forem favoráveis à criação de uma base de orientação propícia à situação, sem dúvida, os estudantes terão mais dificuldades para lidar com a escrita do texto.

Apesar de a atividade ser pouco favorável à expressão dos alunos, destaca-se o esforço da docente em propor situações em que os estudantes 
foram chamados a argumentar por escrito. Diferentes autores apontam as dificuldades de crianças produzirem textos da ordem do argumentar. (OOSTDAN, GLOPPER; EITING, 1994; PIÉRAUT-LE BONNIEC; VALETTE, 1991). É necessário, pois, conduzir o ensino nessa direção.

A professora 2, conforme foi discutido neste tópico, apesar de ter possibilitado contato com textos da ordem do argumentar, não aprofundou reflexões que ajudassem os alunos a analisar estratégias discursivas dos autores ou mesmo produzir textos da ordem do argumentar. Apesar disso, favoreceu, por meio de uma atividade em dupla, a discussão pelas crianças de uma questão em que era necessário precisariam argumentar acerca de valores, informações ou tema mobilizados no texto: as atitudes dos humanos para com os outros animais.

\section{Professora 3}

A professora 3 regia uma sala de 37 alunos, no turno da tarde. Tinha 45 anos, era formada em Pedagogia com 27 anos de experiência docente.

Nas aulas observadas, foram usados poemas, letras de música, quadrinhas e textos didáticos, perfazendo um total de 18 textos. Tais textos foram levados em livros didáticos e jornais. Foram utilizados também textos escritos no quadro ou mimeografados. Uma análise pormenorizada dos textos levados pela professora mostra que alguns deles possibilitavam trabalhos voltados para a argumentação, pois tratavam de temas polêmicos ou questões sociais passíveis de debate. Tal fato denota preocupação da docente com a necessidade de ensinar os alunos a lidar com essas temáticas.

O texto usado em uma das aulas foi sobre o dia internacional da mulher e possibilitou reflexões sobre os direitos conquistados pelas mulheres ao longo do tempo, suas demandas de trabalho atuais e conflitos vividos. O texto contava a história das mulheres que morreram queimadas numa fábrica de Nova lorque, ao buscarem melhores condições de trabalho. A professora falou das conquistas que as mulheres já tiveram ao longo da história (melhoria salarial, direito ao voto e respeitol e pediu para os alunos abrirem o caderno de História. Colocou o texto no quadro e pediu que eles copiassem no caderno. Após esse momento, a docente pediu para que os alunos da primeira fila encontrassem, no parágrafo 1, algumas palavras com encontro consonantal. 
Depois, fez o mesmo com os alunos da segunda fila, agora, com o foco no parágrafo 2, e assim por diante. Em seguida, discutiu sobre a importância dos parágrafos e, por fim, produziu, coletivamente, com os alunos um cartaz sobre os direitos da mulher. Como se pode verificar, apesar de selecionar um texto que favorecia a emergência de situações de aprendizagem de habilidades argumentativas, a professora não conseguiu promover situações em que os estudantes confrontassem seus pontos de vista.

No final da aula descrita, a docente propôs uma tarefa de casa em que as crianças foram solicitadas a responder por escrito algumas perguntas sobre o texto. Segue a atividade encaminhada:

\section{Atividade de casa}

Responda lendo o texto sobre o dia da mulher.

1 - Em que cidade aconteceu o fato que levou a termos um dia especial para as mulheres?

2 - Por que, em 1908, as mulheres saíram em passeata levando cartazes?

3 - O que significava a frase: "pão e rosas!"?

4 - Quantos anos faz que mulheres morreram em uma fábrica, por melhores condições de trabalho em Nova lorque?

5 - Escreva, com suas palavras, por que existe o dia Internacional da mulher.

Como se percebe, as questões estimulavam a busca pelos sentidos textuais, contemplando diferentes estratégias de leitura, mas favoreciam pouco a discussão sobre possíveis divergências em relação ao tema dos direitos da mulher.

Ao longo das observações, vê-se ainda, que a professora lia com as crianças textos que favoreciam reflexões de natureza argumentativa. Porém, as questões formuladas para a discussão priorizavam uma leitura mais literal, não sendo aproveitado esse potencial dos textos e dos temas por eles abordados.

Com relação às atividades de produção de textos observadas na sala da professora 3, foram destacados ainda, algumas tentativas de promover situações de escrita em que as crianças pudessem se posicionar criticamente. Porém, assim como o que ocorreu com a professora 2, problemas relativos às condições de produção da escrita comprometeram a atividade. 
Em uma das aulas, por exemplo, a professora, após fazer uma breve explanação sobre o Aniversário de Recife e Olinda (cidades onde as crianças residiam), sugeriu a seguinte atividade: "Crie um texto de como você pode respeitar a cidade do Recife." Nota-se que o comando não deixa muito claro para as crianças a finalidade da escrita, afinal, a própria ideia de "respeito por uma cidade" precisaria ter sido mais discutida. A falta de especificação do gênero textual também foi uma lacuna verificada nesse e em outros comandos para a produção de textos registrados no período de observação.

Em suma, a situação gerada para a escrita não auxiliou as crianças a construir uma base de orientação que favorecesse o resgate de experiências significativas com a língua para apoiar a escrita do texto. Os destinatários, assim como ocorreu em outras aulas, permaneceram restritos aos participantes do momento de escrita: "Escrevam um texto bem bonito, porque você vai ler depois para mim e para os colegas em voz alta." Leal e Morais (2006), ao analisarem textos de crianças, perceberam que os estudantes que participavam de situações de ensino em que as professoras estimulavam a escrita em situações diversificadas quanto aos gêneros, finalidades e destinatários produziam textos em que havia um maior atendimento à situação de interação; os que eram expostos a situações vagas de escrita "sobre temas gerais", apenas para o professor e colegas (redação escolar) tinham mais dificuldades em escrever um texto claro. Muitos desses textos, por exemplo, só poderiam ser entendidos pelas pessoas que estavam presentes, pois havia referências a informações que só eram conhecidas do grupo classe.

Em outro dia de aula, problemas semelhantes aos apontados acima reapareceram. A professora solicitou que os alunos escrevessem "um texto para falar sobre o bairro onde moravam, falando sobre as coisas ruins, como violência, esgoto e lixo". Tal proposta, que também não apresentava indicação de interlocutores, poderia ter sido pensada como um bom momento para que eles escrevessem uma carta de reclamação ou uma carta aberta à comunidade. No entanto, a situação de escrita encaminhada e o comando para a produção (escreva um texto sobre...) não orientavam, claramente, o aluno no sentido de escrever um texto em que precisaria defender algum ponto de vista. 


\section{Professora 4}

A professora 4 tinha 30 anos, com 13 anos de experiência como professora e sua sala era composta de 22 alunos. A docente havia concluído os cursos de Magistério e de Ciências da Computação, mas ainda estava cursando Pedagogia.

As observações das 15 aulas evidenciaram uma tendência de a professora utilizar textos didáticos, embora outros gêneros textuais tenham sido lidos: letra de música, poema, instrução para experimento científico, conto. A grande maioria dos textos foi levada para sala de aula nos livros didáticos de Língua Portuguesa e Ciências, não havendo um estímulo para a leitura em outros suportes textuais.

Os temas abordados e algumas situações de interação, sobretudo, aquelas decorrentes de discussão oral promovida pela professora, favoreceram o desenvolvimento de estratégias argumentativas.

As práticas de leitura de textos foram desenvolvidas em nove, dos quinze dias observados. Chamou-se a atenção para os variados momentos quando a professora solicitou aos alunos a cópia de textos no caderno. Nos casos dos textos longos, a cópia consumia quase a metade do período da aula.

Apesar desse desperdício, nas atividades de leitura a professora 4 sempre buscava contextualizar os temas dos textos propostos, aproximando-os das vivências das crianças, bem como promovendo relações intertextuais.

Além disso, diversas foram as situações que precederam ou antecederam a leitura de textos em que a professora explorou o tema a partir de discussões orais. Algumas dessas discussões, em função do tema abordado e dos questionamentos lançados pela professora, somados a opiniões do autor identificadas em alguns textos, favoreceram situações didáticas de exploração de estratégias argumentativas. Porém, tal exploração não foi observada. Apesar disso, assim como ocorreu com as professoras 1 e 3, foi possível identificar um esforço em selecionar textos que propiciavam o contato com estratégias argumentativas. Talvez houvesse mesmo uma concepção de que a aprendizagem ocorreria por imersão, apenas pelo contato com os textos, conforme foi discutido em relação à professora 1 . 
Quanto às situações de produção escrita, identificaram-se também algumas possibilidades de produção de textos da ordem do argumentar. Entretanto, tais situações se mostraram pouco favoráveis à reflexão sobre as estratégias discursivas que podem ser mobilizadas nesse contexto de produção. Em uma das aulas, por exemplo, após uma discussão sobre o tema da "deficiência", a professora solicitou a produção de cartazes e encartes educativos sensibilizando para os direitos das pessoas com deficiência. As crianças, porém, não conseguiram produzir textos semelhantes aos gêneros de circulação social veiculados em campanhas educativas. Sem a mediação da professora, que não estimulou a reflexão sobre as características discursivas e composicionais do gênero, elas acabaram produzindo cartazes com informações sobre o tema, sem refletir sobre o gênero cartaz educativo e buscar os efeitos de sentido presentes em seus exemplares.

Em outro dia de observação, a tarefa de casa fez referência aos direitos dos idosos. O diálogo sobre os direitos dos idosos sugeria a produção de um texto da ordem do argumentar, mas a docente solicitou a realização de um desenho e a criação de uma "história sobre o desenho".

Numa aula seguinte, foi registrada uma única situação em que foi 194 solicitada a produção de texto para a defesa de pontos de vista. A professora comandou uma discussão sobre a história do Brasil. Dentre outras perguntas, indagava se os índios eram independentes antes e depois que os portugueses chegaram ao Brasil. A professora escrevia, no quadro, as respostas dos alunos, buscando construir um texto. Depois, solicitou que eles, individualmente, escrevessem um texto a partir da pergunta: "O Brasil é um país independente?". Como se pode observar, o tema demandava a produção de um texto argumentativo. No entanto, observa-se que, mais uma vez, não houve indicação de gênero (ficando implícito que seria uma redação escolar), destinatários ou espaço social de interação. Além disso, não houve nenhuma orientação adicional que estimulasse o desenvolvimento de habilidades necessárias à argumentação escrita. Os textos foram entregues à professora e não houve discussão sobre as ideias apresentadas pelas crianças.

Diante do exposto, nota-se que, nas aulas analisadas, a professora teve dificuldade em propor situações miméticas às praticadas fora da escola. E, embora tenham sido registradas várias situações que poderiam ser aproveitadas para estimular habilidades argumentativas, isso não ocorria. 


\section{Professora 5}

A professora 5 tinha 61 anos e era a única que não havia concluído um curso superior. Tinha 26 anos de experiência e habilitação em Magistério. Sua turma do $5^{\circ}$ ano tinha 20 alunos.

Assim como as demais docentes, utilizava variados gêneros textuais em suas aulas: letra de música, carta pessoal, panfleto de proposta eleitoral, Constituição Brasileira, relato histórico, mapas, texto didático. Alguns desses textos possibilitavam atividades voltadas para o desenvolvimento de capacidades argumentativas.

Em uma das aulas, após a leitura de um trecho da Constituição Brasileira, os alunos discutiram sobre o referendo acerca do desarmamento. Foram contempladas, dessa maneira, habilidades relativas à emissão de opinião e análise de diferentes pontos de vista sobre um tema. Tal situação pode ser considerada, tomando de empréstimo a denominação usada por Dolz, Schneuwly e Pietro (2004), um debate de fundo controverso, ou seja, um debate em que as pessoas confrontam pontos de vista sobre algum tema polêmico. Na verdade, nessa época, toda a sociedade estava engajada nesse debate e muitos argumentos estavam circulando na mídia e nos espaços da vida privada. Assim, já havia uma motivação instalada para a discussão dessa temática e a professora mostrou, com sua proposta, a preocupação com a formação cidadã de seus alunos. Ressalta-se, porém, que a mediação da professora foi pouco problematizadora, não estimulando os alunos a confrontar as justificativas e contra-argumentos que emergiram na discussão. Assim, as crianças eram, apenas, estimuladas a expressar sua opinião que deveria ser ouvida e respeitada por todos. Além disso, a atividade poderia ter suscitado interessantes desdobramentos; e isso não ocorreu. Por exemplo, o convite de pessoas que defendessem diferentes posições para expor seu ponto de vista e a organização de um debate mais formal ou um júri simulado. Em outra aula observada, após lerem um relato histórico sobre a sociedade pernambucana, os alunos debateram sobre a vida em sociedade, a importância das normas e leis e sobre o trabalho escravo, temas tratados no texto. Mais uma vez, foram propiciados momentos ricos de exposição de diferentes pontos de vista sobre temas sociais relevantes. As situações, além de promoverem condições favoráveis de desenvolvimento de habilidades de emitir opinião e analisar 
argumentos alheios, também favoreceram a ampliação de conhecimentos dos estudantes acerca do tema em discussão.

Finalmente, foi identificada uma terceira aula, em que os alunos, após realizarem leitura de mapas, discutiram sobre suas preferências por mapas novos ou antigos. Embora a discussão não envolvesse um tema polêmico, os estudantes foram estimulados a expressar seus gostos pessoais, justificar suas preferências e a respeitar as opiniões de seus pares, habilidades importantes em situações que envolvem a argumentação. Em síntese, nota-se que a professora 5 traz para a sala temas e textos que instigam o debate e que, portanto, poderiam ajudar os alunos a desenvolver capacidades argumentativas.

Quanto ao eixo de produção de textos, diferentemente do que aconteceu com o eixo de leitura, não foram identificadas propostas em que os alunos tivessem que defender pontos de vista. Nas 15 aulas observadas, foram desenvolvidas seis atividades de escrita de textos, mas nenhuma explorava a produção de textos da ordem do argumentar.

\section{Considerações finais}

Como se pode verificar, das 75 aulas observadas, só aconteceram seis situações de leitura de textos de modo a desenvolver capacidades argumentativas (três dessas foram conduzidas pela professora 5). Quanto à produção de textos, das 75 aulas, foi observada apenas uma aula em que a professora 2, de fato, propôs uma situação em que as crianças teriam que escrever para defender um ponto de vista.

Tal escassez, realmente, revela pouco investimento no ensino de conhecimentos e habilidades importantes no cotidiano de qualquer indivíduo. Não há ainda no currículo vivido em muitas escolas brasileiras investimento no ensino voltado para o "[...] desenvolvimento de argumentos e de mobilização de enunciados; a possibilidade de cada um latravés do funcionamento do debate) de intervir livremente quando quiser; a capacidade de centralizar-se nos objetos em jogo e de engendrar novos temas que daí decorram; o respeito à palavra do outro e a integração desta ao nosso próprio discurso." (SCHNEUWLY; DOLZ, 2004, p. 85).

No entanto, apesar do nítido baixo investimento no desenvolvimento de habilidades argumentativas das crianças que concluem a primeira etapa 
do Ensino Fundamental, foram identificados alguns caminhos nessa direção. Assim, ao que parece, de modo intuitivo, as professoras vão propondo situações em que habilidades argumentativas são mobilizadas.

Como discutido anteriormente, de modo geral, as docentes comumente liam textos autênticos de diferentes gêneros e, com exceção da professora 4, preocupavam-se em diversificar suportes textuais. Elas propunham não, apenas, a leitura em voz alta dos textos, mas também elaboravam questões de interpretação pertinentes e que, algumas vezes, demandavam habilidades argumentativas. Como se percebe, com exceção da professora 4 , as demais docentes estimulavam a expressão de opiniões sobre certos temas polêmicos, textos lidos ou filmes a que haviam assistido. No entanto, a mediação docente pouco favorecia o confronto de opiniões. As concepções que pareciam embasar a prática era que se os alunos fossem expostos a textos em que temas polêmicos fossem utilizados, as habilidades argumentativas emergiriam. Não parecia haver nenhum planejamento mais voltado para provocar a mobilização das diferentes habilidades argumentativas. Por exemplo, não havia questões em que os estudantes buscassem identificar os pontos de vista dos autores dos textos, confrontando-os com seus próprios pontos de vista, ou situações em que textos que contivessem diferentes pontos de vista sobre um tema fossem comparados.

As propostas de escrita de textos eram menos frequentes e, geralmente, não faziam referência a situações de interlocução semelhantes às vivenciadas nos contextos extraescolares, sobretudo, aquelas propostas pelas professoras 2, 3 e 4 . Havia, portanto, um movimento de aproximação e afastamento entre atividades de escrita mais estritamente "escolares" e aquelas envolvendo contextos de interação extraescolares.

Em relação às práticas de produção de textos da ordem do argumentar, foi observado que as dificuldades das docentes eram enormes. Os comandos das atividades eram pouco propícios ao engajamento das crianças nas propostas de trabalho. Eles não vivenciavam situações em que tivessem que convencer destinatários sobre seus pontos de vista e nem persuadi-los a adotar posturas ou atitudes sociais.

Assim, apesar da escassez de orientações, as docentes tentaram contemplar o ensino de habilidades argumentativas, mas tal ensino era pouco reflexivo, centrado, apenas, em questões que solicitavam a emissão de opinião 
sobre o tema do texto, sem exploração das pistas textuais para identificação dos posicionamentos dos autores e relações com outros textos. Parecia haver uma concepção de que os alunos aprenderiam por imersão (lendo/discutindo/produzindo desenvolveriam habilidades argumentativas). Isto é, não era oportunizada de modo consistente uma reflexão sobre estratégias discursivas.

A frequência de situações de ensino em que as docentes seguiam um padrão fixo na organização didática é outro aspecto que se pode mencionar. Via de regra, o modelo de aula era:

Ler / passar filme ou levantar uma questão / discutir em grupo (ou)

Ler / passar filme ou levantar uma questão / discutir em grupo / produzir texto de opinião (mais raramente)

Desse modo, é pertinente ponderar se, nos processos formativos, os professores são incentivados a criar suas próprias estratégias para que possam analisar as suas experiências de ensino e, assim, transformar rotinas predefinidas em vivências mais reflexivas. A esse respeito, Barros (2008, p. 90) atenta que:

Os processos de formação que partem de modelos a priori sobre o trabalho docente, negligenciando o trabalho real, ou seja, as atividades que se engendram no cotidiano da escola, correm o risco de produzir fôrmas-de-ação e não outras formas de ação. (BARROS, 2008, p. 901.

Frente a tal questão, é pertinente propor que o ensino da argumentação seja objeto de reflexão em projetos de formação continuada de professores, de modo sistemático e aprofundado, partindo-se das experiências concretas dos docentes, para que se possa estimular práticas pedagógicas em que haja maior articulação entre a escola e outras esferas sociais de interação. Por isso, corroboramos com Oliveira a ideia de que:

Se queremos pensar em melhorar essas práticas, precisamos, portanto, criar, não novas normas, mas novos modos de interação entre a academia, seus saberes e fazeres específicos e os saberes e fazeres dos docentes que estão nas escolas. E isso só será possível se respeitamos esses saberes para que o diálogo democrático possa se estabelecer. (OLIVEIRA, 2008, p. 66). 


\section{Referências}

ANDRADE, Renata Lessa; LEAL, Telma Ferraz; BRANDÃO, Ana Carolina Perrusi. A presença do texto da ordem do argumentar no livro didático destinado às séries iniciais. In: ENCONTRO NACIONAL DE DIDÁTICA E PRÁTICA DE ENSINO (ENDIPE), 13., 2006, Recife. Anais... Recife: Universidade Federal de Pernambuco, 2006. 1 CD-ROM.

BAKHTIN, Michael. Estética da criação verbal. 3.ed. São Paulo: Martins Fontes, 2000.

BARDIN, Laurence. Análise de Conteúdo. Tradução Luís Antero Reto e Augusto Pinheiro. Lisboa: Edições 70, 2004.

BARROS, Maria Elizabeth Barros de. Formação de professores / as e os desafios para a (re) invenção da escola. FERRAÇO, Carlos Eduardo. Cotidiano escolar, formação de professores (as) e currículo. 2. ed. São Paulo: Cortez, 2008.

BEZERRA, Maria Auxiliadora. Textos: seleção variada e atual. In: DIONISIO, Angela; BEZERRA, Maria Auxiliadora (Org.). O livro didático de português: múltiplos olhares. Rio de Janeiro: Lucerna, 2001 . p. 33-45.

BRASSART, Dominique Guy. Explicatif, argumentatif, descriptif, narratif et quelques autres, notes de travail, Recherches, n. 13, p. 21-59, 1990.

CANVAT, Karl. Types de textes et genres textuels: problématique et enjeus. Enjeux, n. 37-38, p. 5-30, 1996,

DOLZ, Joaquim; SCHNEUWLY, Bernard. Gêneros e progressão em expressão oral e escrita: elementos para reflexões sobre uma experiência suiça (Francófona). In: SCHNEUWLY, Bernard; DOLZ, Joaquim. Gêneros orais e escritos na escola. Tradução Glaís Sales Cordeiro e Roxane Rojo. Campinas: Mercado de Letras, 2004.

DOLZ, Joaquim; SCHNEUWLY, Bernard; PIETRO, Jean-François. Relato da elaboração de uma sequência: o debate público. SCHNEUWLY, Bernard \& DOLZ, Joaquim. Gêneros orais e escritos na escola. Tradução Glaís Sales Cordeiro e Roxane Rojo, Campinas, São Paulo: Mercado de Letras, 2004.

JAUSS, Hans-Robert. Littérature medievale et théorie des genres. Poétiques, n. 1, p. 79-101, 1970.

LEAL, Telma Ferraz; MORAIS, Artur Gomes. A argumentação em textos escritos: a criança e a escola. Belo Horizonte: Autêntica, 2006 
LEAL, Telma Ferraz; BRANDÃO, Ana Carolina Perrusi; TORRES, Mirela. Leitura nos livros didáticos: a identificação de pontos de vista em textos escritos como objeto de ensino. Revista Educação em Questão, Natal, v. 34, n. 20, jan./abr. p. 220-243. 2009.

LOPES, Sâmea. Dissertar: uma perspectiva possível na alfabetização. Recife, 1998, Monografia (Especialização em Educação) - Centro de Educação, Universidade Federal de Pernambuco, Recife, 1998. 30 pág.

MENDONÇA, Márcia. Língua e ensino: políticas de fechamento. In Mussalim, Fernanda. \& Bentes, Anna Christina. Introdução à lingüística: domínios e fronteiras. 2. ed. São Paulo: Cortez, 2001. (v. 2).

OLIVEIRA, Inês Barbosa. Criação curricular, autoformação e formação continuada no coti-diano escolar. In: FERRAÇO, Carlos Eduardo. Cotidiano escolar, formação de professores (as) e currículo. 2. ed. São Paulo: Cortez, 2008.

OOSTDAM, Ron; GLOPPER, Kees. \& EITING, Mindert. Argumentation in written discourse: secondary school students' writing problems. In: VAN EEMEREN, Frans H; GROOTENDORST, Rob (Ed.). Studies in Pragma-dialects. Amsterdam: Sec. Sat, 1994.

PIÉRAUT-LE BONNIEC, Gilberte \& VALETTE, M. The development of argumentative discourse. 200 In: Piéraut-Le Bonniec, Gilbert \& Dolitsky, Marlene (Ed.). Language bases and discourse base. Amsterdam: John Benjamins Publishing Company, 1991.

REINALDO, Maria Augusta. A orientação para produção de texto. In: Dionísio, Angela. \& Bezerra, Maria Auxiliadora. O livro didático de português: múltiplos olhares. Rio de Janeiro: Lucerna, 2001.

SCHNEUWLY, Bernard \& DOLZ, Joaquim. Os gêneros escolares: das práticas de linguagem aos objetos de ensino. Revista Brasileira de Educação, São Paulo, v. 1, n. 11, p. 5-16, maio/ago. 1999,

SCHNEUWLY, Bernard. Le language écrit chez l'enfant - La production des textes informatifs et argumentatifs. Neuchâtel: Delachaux et Niestlé, 1998.

SCHNEUWLY, Bernard. Les operations langagieres. In: SCHNEUWLY, Bernard. Le language ecrit chez l'enfant. Paris: Delachaux \& Niestle, 1988.

SOUZA, Lusinete. As proezas das crianças em textos de opinião. Campinas: Mercado de Letras, 2003. 
Profa. Dra. Telma Ferraz Leal Universidade Federal de Pernambuco | Recife Centro de Educação Programa de Pós-Graduação em Educação Membro do Centro de Estudos em Educação e Linguagem E-mail | ffleal@terra.com.br

Profa. Dra. Ana Carolina Perrusi Brandão Universidade Federal de Pernambuco | Recife Centro de Educação Programa de Pós-Graduação em Educação Membro do Centro de Estudos em Educação e Linguagem E-mail | carol.perrusi@ufpe.br Apoio do CNPq

Recebido 23 maio 2013 Aceito 23 set. 2013 